\title{
Posttraumatic infrarenal abdominal aortic pseudoaneurysm treated with bifurcated endovascular graft stent
}

\author{
Ender Oner ${ }^{1}$, Korhan Erkanli², Ibrahim Faruk Akturk ${ }^{1}$, Unal Aydin², Okan Akinci ${ }^{3}$, Aydin Yildirim ${ }^{1}$ \\ ${ }^{1}$ Cardiology Department, Mehmet Akif Ersoy Thoracic and Cardiovascular Surgery Training and Research Hospital, Istanbul, Turkey \\ ${ }^{2}$ Cardiovascular Surgery Department, Mehmet Akif Ersoy Thoracic and Cardiovascular Surgery Training and Research Hospital, Istanbul, \\ Turkey \\ ${ }^{3}$ Radiology Department, Mehmet Akif Ersoy Thoracic and Cardiovascular Surgery Training and Research Hospital, Istanbul, Turkey
}

Postep Kardiol Inter 2015; 11, 2 (40): 146-149

DOI: $10.5114 /$ pwki.2015.52289

\begin{abstract}
A bstract
Posttraumatic infrarenal aortic pseudoaneurysms are rare and potentially lethal lesions. We report the case of a 32-year-old man presenting with infrarenal aortic pseudoaneurysm eight months after being stabbed in the back and right flank. His pseudoaneurysm was close to the iliac bifurcation, so we decided to deploy a bifurcated endovascular graft stent, the TriVascular Ovation endovascular stent. Imaging one month after the procedure revealed no endoleak and slight shrinkage of the pseudoaneurysm.
\end{abstract}

Key words: abdominal aortic pseudoaneurysm, endovascular repair, trauma.

\section{Introduction}

Traumatic pseudoaneurysms of the abdominal aorta are rare, because aortic injury frequently results in death [1]. Traumatic pseudoaneurysms of the abdominal aorta occur mainly as a consequence of penetrating trauma [2-4], but blunt trauma can also cause pseudoaneurysms

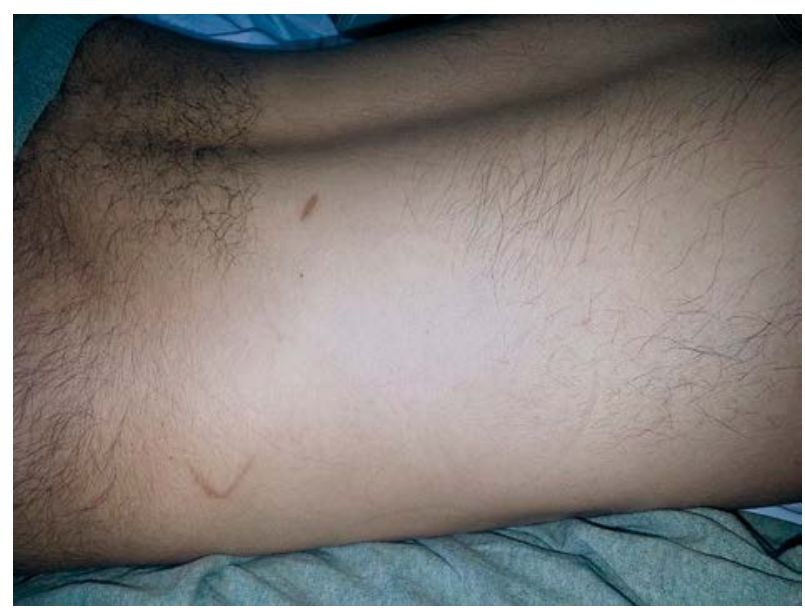

Figure 1. Stabbing wounds at patient's back and right flank
[5]. When an arterial injury is left untreated, local hemorrhage tamponed by surrounding tissues can cause pulsatile hematoma. With absorption of the hematoma and fibrosis of surrounding tissue, a chronic pseudoaneurysm forms [1].

\section{Case report}

A 32-year-old man was admitted to our emergency department with severe abdominal pain. He had a history of stabbing in several regions of his body (left shoulder, under the left nipple, the right flank and back) sustained in a fight 8 months previously. He was admitted to a hospital at the time, but the medical records from that hospitalization could not be obtained. However, as learned from the patient, after 1 day of observation in the emergency department, his wounds were considered superficial and he was discharged from the hospital. One month after that event, the patient started to complain of abdominal pain, and he was admitted to the hospital several times for this complaint. He was admitted to our hospital after the abdominal pain increased over the course of 3 days. On physical examination the patient's heart rate was 82 beat/min, his arterial blood pressure was $130 / 70 \mathrm{~mm} \mathrm{Hg}$, and his hemoglobin was $14 \mathrm{~g} / \mathrm{dl}$. The

\section{Corresponding author:}

Ender Oner MD, Cardiology Department, Mehmet Akif Ersoy Thoracic and Cardiovascular Surgery Training and Research Hospital, İstasyon Mah. Turgut Ozal bulvarı N0: 11 Kucukcekmece, 34303 Istanbul, Turkey, phone: +90 212692 20 00, e-mail: enderoner7@gmail.com

Received: 27.04.2014, accepted: 9.06.2014. 

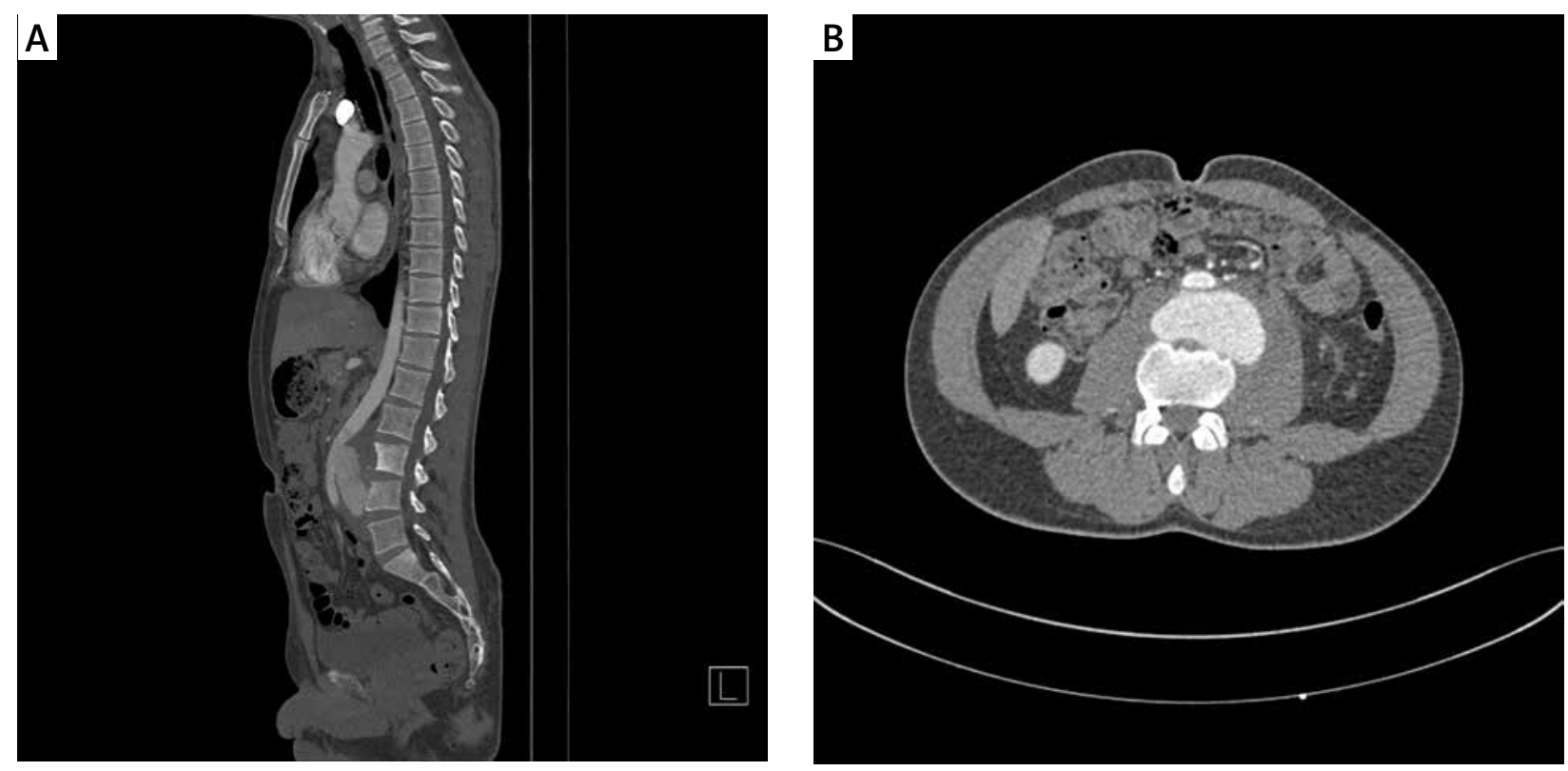

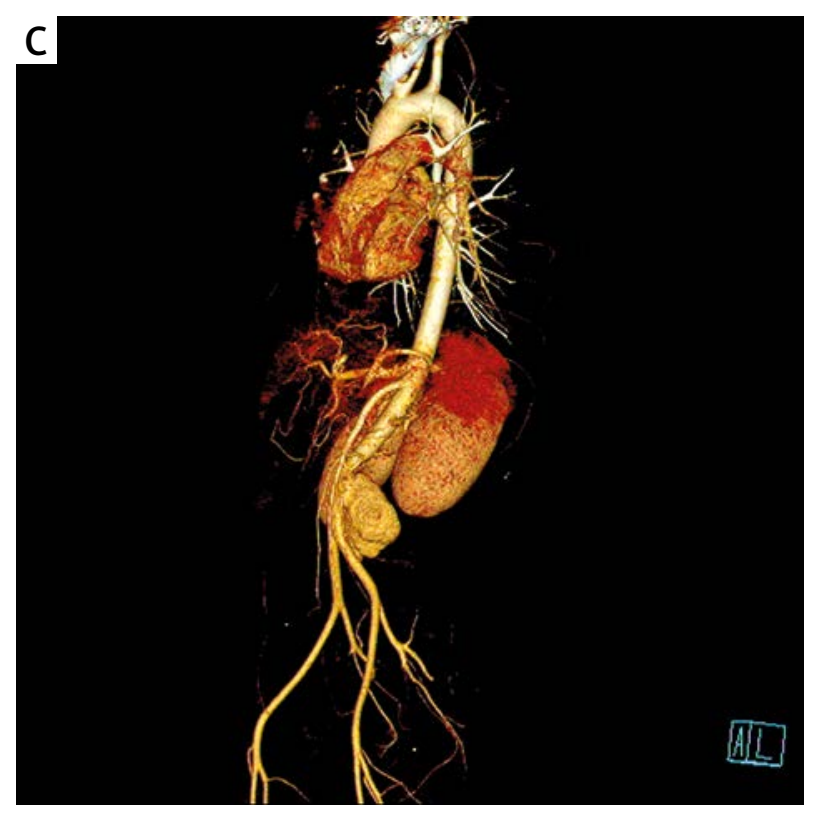

knife stab wounds could be seen (Figure 1). Computed tomography angiography (CTA) revealed an abdominal aortic pseudoaneurysm, $92 \times 91 \times 26 \mathrm{~mm}$ in size, arising from the posterior abdominal aorta $50 \mathrm{~mm}$ below the left renal artery, with a defect size of $23 \times 16 \mathrm{~mm}$ (Figure 2). The iliac bifurcation was $17 \mathrm{~mm}$ below the aortic injury. Erosion of $\mathrm{L} 3$ due to compression of the aortic pseudoaneurysm was also seen (Figure 2). The neck of the pseudoaneurysm was close to the iliac bifurcation, so we decided to implant an endovascular stent. On the same day that the patient was admitted to our hospital, we deployed a 26-mm aortic body ovation stent (TriVascular, Inc., Santa Rosa, CA) under the left renal artery, with a $12 \times 100-\mathrm{mm}$ iliac limb deployed to the right iliac artery and a $14 \times 180$ $\mathrm{mm}$ iliac limb deployed to the left common iliac artery.
Figure 2. Computed tomography angiography images at presentation. A - Sagittal view of the pseudoaneurysm showing anterior displacement of abdominal aorta. B - Erosion of $\mathrm{L} 3$ due to compression of aortic pseudoaneurysm. $\mathbf{C}-3 \mathrm{D}$ reconstruction of CTA showing pseudoaneurysm close to iliac bifurcation

The patient was discharged on the fifth day after the procedure. Computed tomography angiography performed one month after the procedure revealed no endoleak and slight shrinkage of the pseudoaneurysm (Figure 3).

\section{Discussion}

Abdominal aortic pseudoaneurysm is a rare and severe complication of aortic injuries. The time interval from initial trauma to diagnosis of the pseudoaneurysm varies from days to years. The longest time interval to diagnosis is 42 years [6]. Since Makins reported the first case of a traumatic pseudoaneurysm of the abdominal aorta in 1920 [7], a small number of cases have been reported. In 1997 Chase et al. [3] reported an abdominal aortic pseudoaneurysm that caused biliary obstruction, and they included a review 


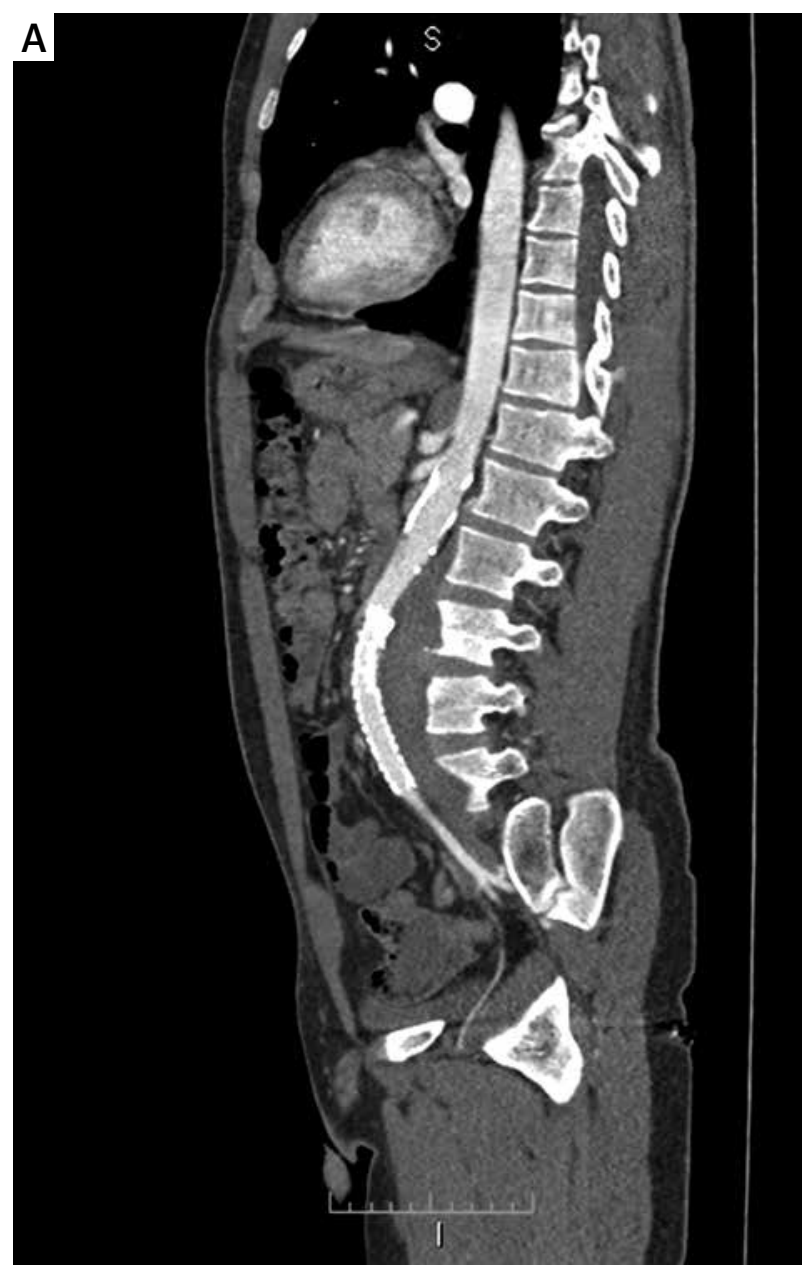

Figure 3. Computed tomography angiography images 1 month after the procedure. A - Sagittal view of the pseudoaneurysm showing slight shrinkage. B - Horizontal CT images with no endoleak. C - 3D reconstruction of CTA showing TriVascular Ovation endovascular stent

of 21 patients with traumatic pseudoaneurysm of the abdominal aorta. Most of the cases (79\%) were caused by penetrating injury. Clinical presentation was variable and included abdominal, back, or chest pain; palpable mass; compression of the renal arteries; upper gastrointestinal bleeding; and inferior vena caval compression. Acute closure of the abdominal aorta due to compression of the pseudoaneurysm has also been reported [8].

Aortic pseudoaneurysms can rupture at any time, and spontaneous rupture has very high mortality rates [3]; therefore, open or endovascular repair is generally mandated. Endovascular repair of the suprarenal abdominal aorta is limited by concerns of possible renal and visceral ischemia. In cases of infrarenal aortic pseudoaneurysms, the preferred surgical approach is pseudoaneurysm re-
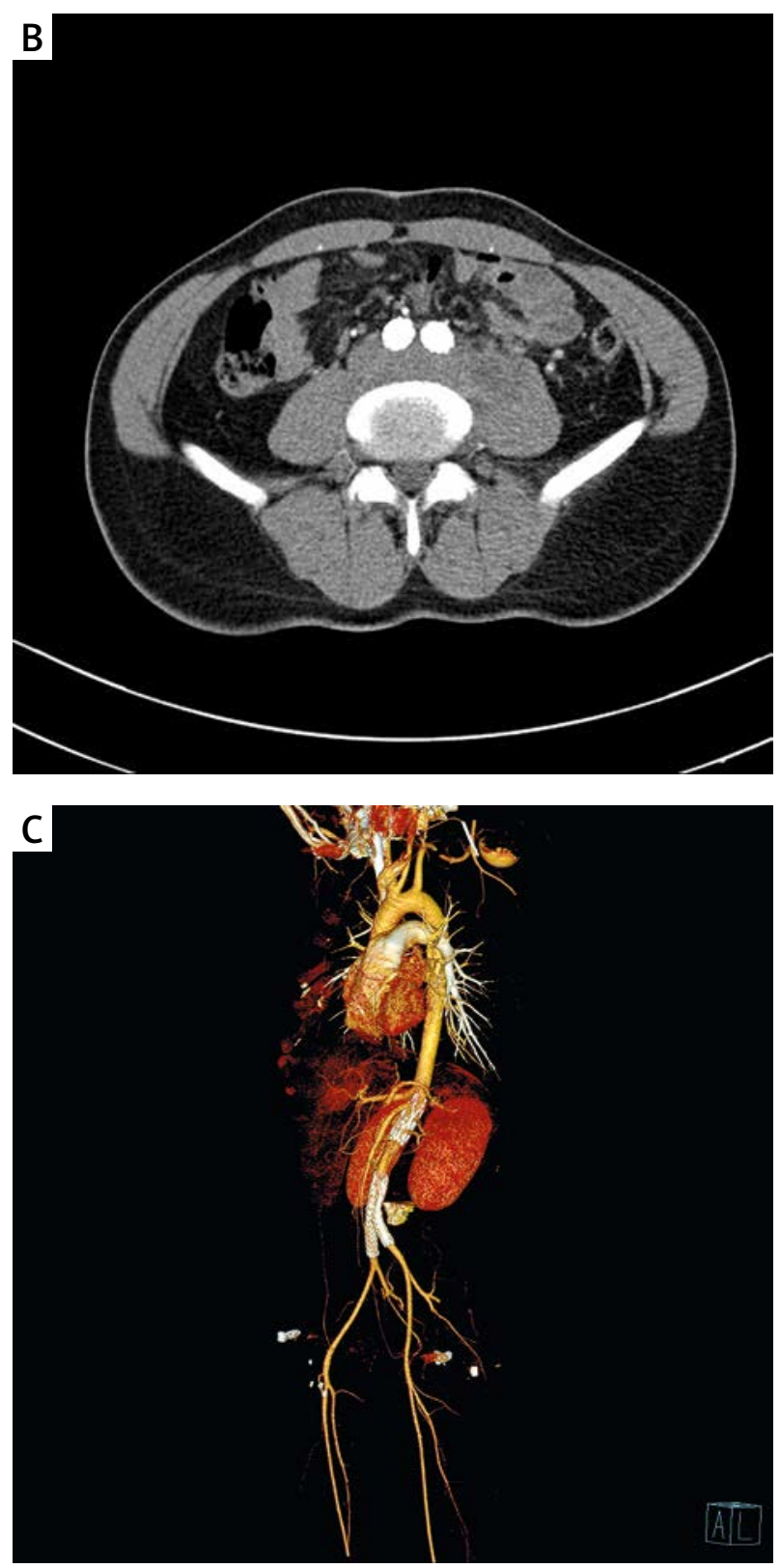

section and graft interposition [9]. In selected cases, alternative treatments such as thrombin injection to the pseudoaneurysm sac have been described [10].

Endovascular repair of infrarenal abdominal aortic aneurysms was first reported by Parodi et al. [11], who used balloon expandable stents. Subsequently, bifurcated endografts were described and implanted by White et al. [12]. Successful endovascular repair of infrarenal abdominal aortic pseudoaneurysms with stent grafts was described in two case reports $[13,14]$ and with a balloon-expandable bifurcated endoprosthesis in one case report [15]. In 1998, Bechara-Zamudio et al. [15] deployed a custom made bifurcated polyester tube in a patient who had undergone six previous abdominal operations with an abdominal aortic pseudoaneurysm above the 
aortic bifurcation. For stabilization, stents were implanted in proximal and iliac ends of the endoprosthesis.

We chose the endovascular treatment option for our patient due to its less invasive nature. The pseudoaneurysm was close to the iliac bifurcation, and there was not enough of a landing zone for a stent graft. Thus, we decided to deploy a bifurcated endovascular graft stent; we used a low-profile TriVascular ovation stent. To the best of our knowledge, this is the first case in which a commercially available bifurcated endovascular stent graft device was used to treat an infrarenal abdominal aortic pseudoaneurysm.

Exploratory laparotomy was not performed for our patient, but in a review [3], 73\% of patients with a pseudoaneurysm underwent exploratory laparotomy and no aortic injury was identified. As suggested by Borioni et al. [9], we think long-term follow-up with ultrasonographic assessment of the abdominal aorta is reasonable, even if there is no evidence of an early retroperitoneal aortic lesion.

\section{Conflict of interest}

The authors declare no conflict of interest.

\section{References}

1. Chaikof EL, Shamberger RC, Brewster DC. Traumatic pseudoaneurysms of the abdominal aorta. J Trauma 1985; 25: 169-73.

2. Potts RG, Alguire PC. Pseudoaneurysm of the abdominal aorta: a case report and review of the literature. Am J Med Sci 1991; 301: 265-8.

3. Chase CW, Layman TS, Barker DE, et al. Traumatic abdominal aortic pseudoaneurysm causing biliary obstruction: a case report and review of the literature. J Vasc Surg 1997; 25: 936-40.

4. Tucker S Jr, Rowe VL, Rao R, et al. Treatment options for traumatic pseudoaneurysms of the paravisceral abdominal aorta. Ann Vasc Surg 2005; 19: 613-8.

5. Pisters PW, Heslin MJ, Riles TS. Abdominal aortic pseudoaneurysm after blunt trauma. J Vasc Surg 1993; 18: 307-9.

6. Queiroz AB, Silva ES, Aun R, et al. Abdominal aortic pseudoaneurysm diagnosed 42 years after abdominal gunshot wound. Clinics 2011; 66: 1113-4.

7. Makins GH. Specimen showing the effects of gunshot injury on the heart and blood vessels: now on exhibit in the museum of the Royal College of Surgeons of England. Br J Surg 1920; 8: 107-32.

8. Li X, Zhao JC, Huang B, et al. Management of giant post-traumatic abdominal aortic pseudoaneurysm and aortic occlusion using a unique hybrid procedure combining transcatheter device closure and open surgical repair. Ann Vasc Surg 2014; 28: 1322.e7-11.

9. Borioni R, Garofalo M, Seddio F, et al. Posttraumatic infrarenal abdominal aortic pseudoaneurysm Tex Heart Ins J 1999; 26: 312-4.

10. Geckeis K, Eggebrecht H, Schmermund A, et al. Percutaneous repair of abdominal aortic pseudoaneurysm by catheter-based delivery of thrombin. J Endovasc Ther 2006; 13: 264-8.

11. Parodi JC, Palmaz JC, Barone HD. Transfemoral intraluminal graft implantation for abdominal aortic aneurysms. Ann Vasc Surg 1991; 5: 491-9.
12. White GH, Yu W, May J, et al. A new nonstented balloon-expandable graft for straight or bifurcated endoluminal bypass. J Endovasc Surg 1994; 1: 16-24.

13. Hussain Q, Maleux G, Heye S, et al. Endovascular repair of an actively hemorrhaging stab wound injury to the abdominal aorta. Cardiovasc Intervent Radiol 2008; 31: 1023-5.

14. Ghazala CG, Green BR, Williams R, et al. Endovascular management of a penetrating abdominal aortic injury. Ann Vasc Surg 2014; 28: 1790.e9-11.

15. Bechara-Zamudio LB, Olive G, Barone H, et al. Traumatic abdominal aortic pseudoaneurysm treated with balloon-expandable bifurcated endoprosthesis. J Vasc Surg 1998; 28: 345-8. 